Supporting Information for:

\title{
Concerted Nature of AB Ring Formation in the Enzymatic Cyclization of Squalene to Hopenes
}

\section{B. Andes Hess, Jr. ${ }^{*}$ and Lidia Smentek}

\section{Structure 3}

\#6-31g* b3lyp nopop freq guess=read geom=check

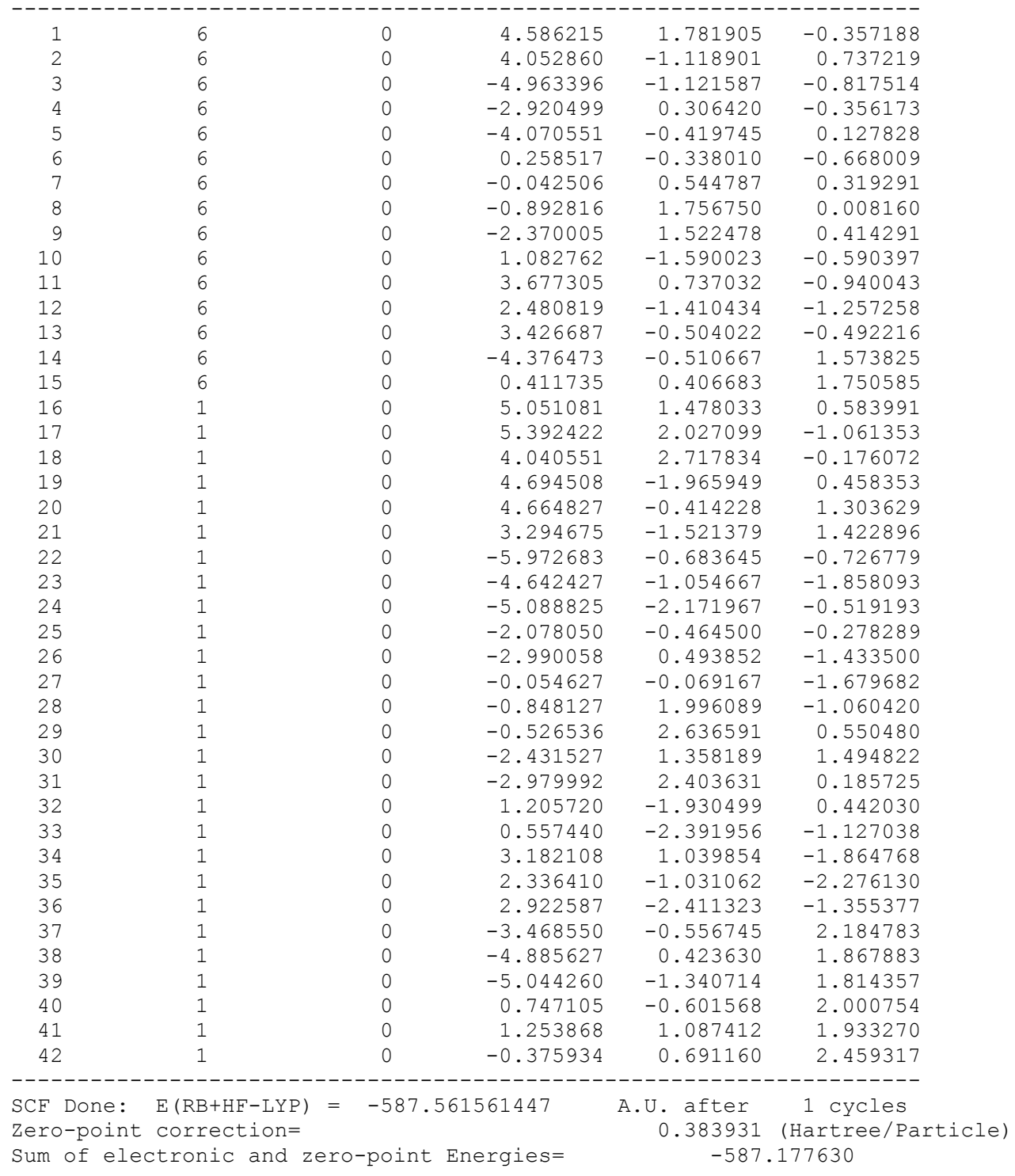




\section{Structure 4}

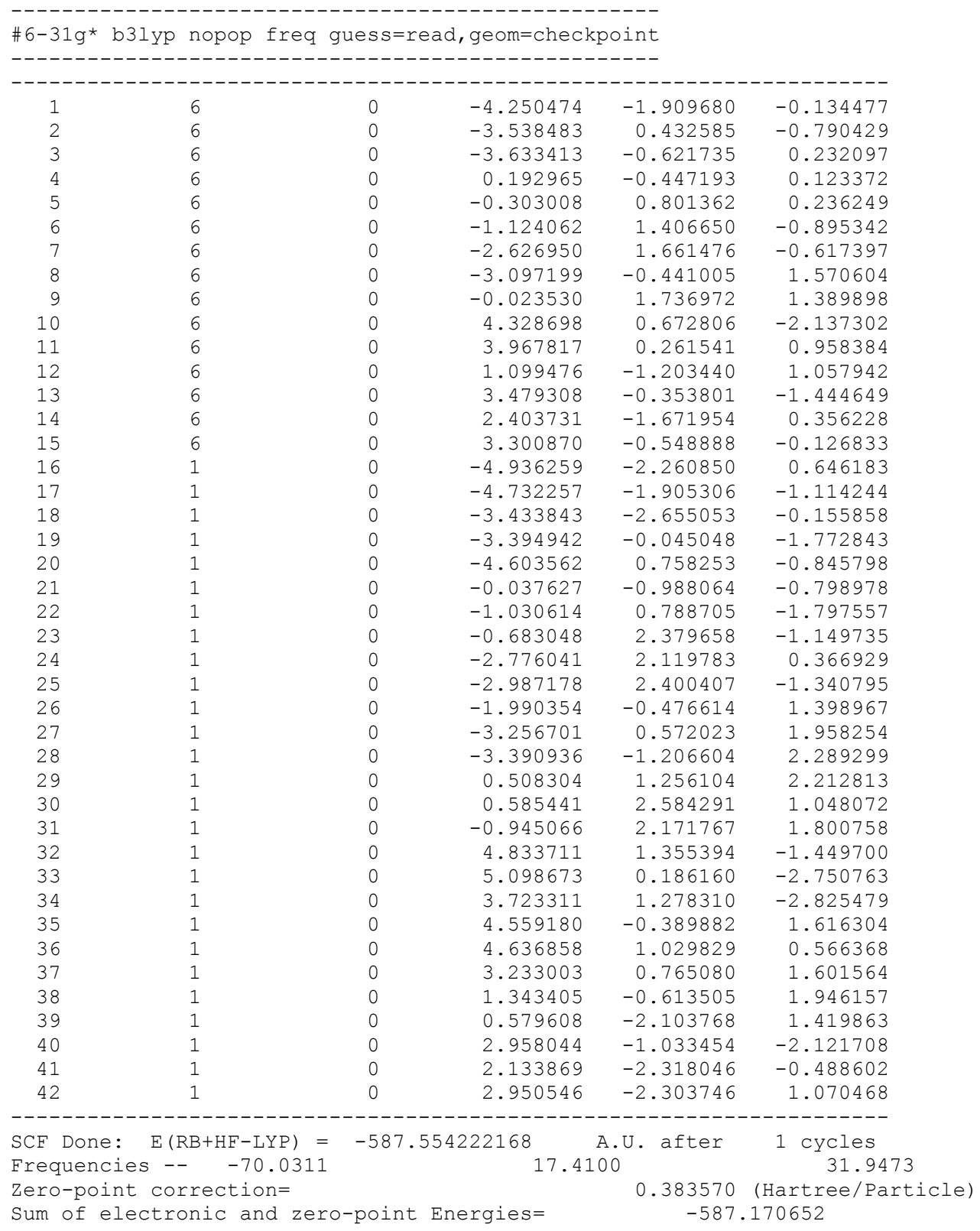

\section{Structure 5}

\#6-31g* b31yP nopop freq guess=read geom=checkpoint

\begin{tabular}{|c|c|c|c|c|c|}
\hline 1 & 6 & 0 & -2.451163 & 0.433915 & -1.288909 \\
\hline 2 & 6 & 0 & -1.986258 & -0.706666 & -0.347244 \\
\hline 3 & 6 & 0 & -0.405006 & -0.682726 & -0.325346 \\
\hline 4 & 6 & 0 & 0.236277 & 0.703227 & -0.018369 \\
\hline 5 & 6 & 0 & -0.303326 & 1.765264 & -0.999068 \\
\hline 6 & 6 & 0 & -1.845327 & 1.802942 & -0.974675 \\
\hline 7 & 6 & 0 & 0.221000 & -1.796541 & 0.514680 \\
\hline 8 & 6 & 0 & 1.899080 & 0.529414 & -0.424537 \\
\hline 9 & 6 & 0 & 1.783959 & -1.864049 & 0.269689 \\
\hline 10 & 6 & 0 & 2.303785 & -0.506420 & 0.495935 \\
\hline
\end{tabular}




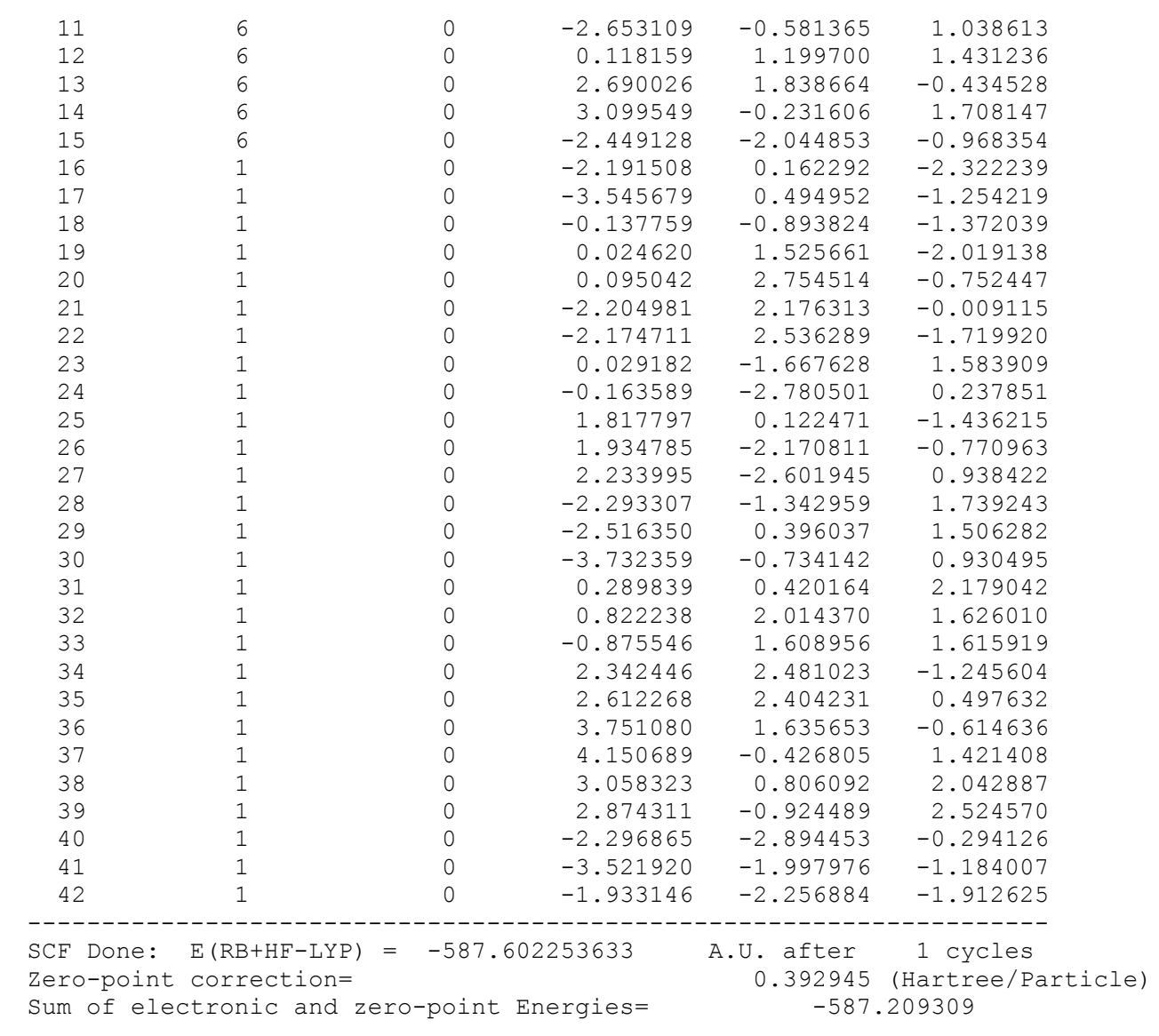




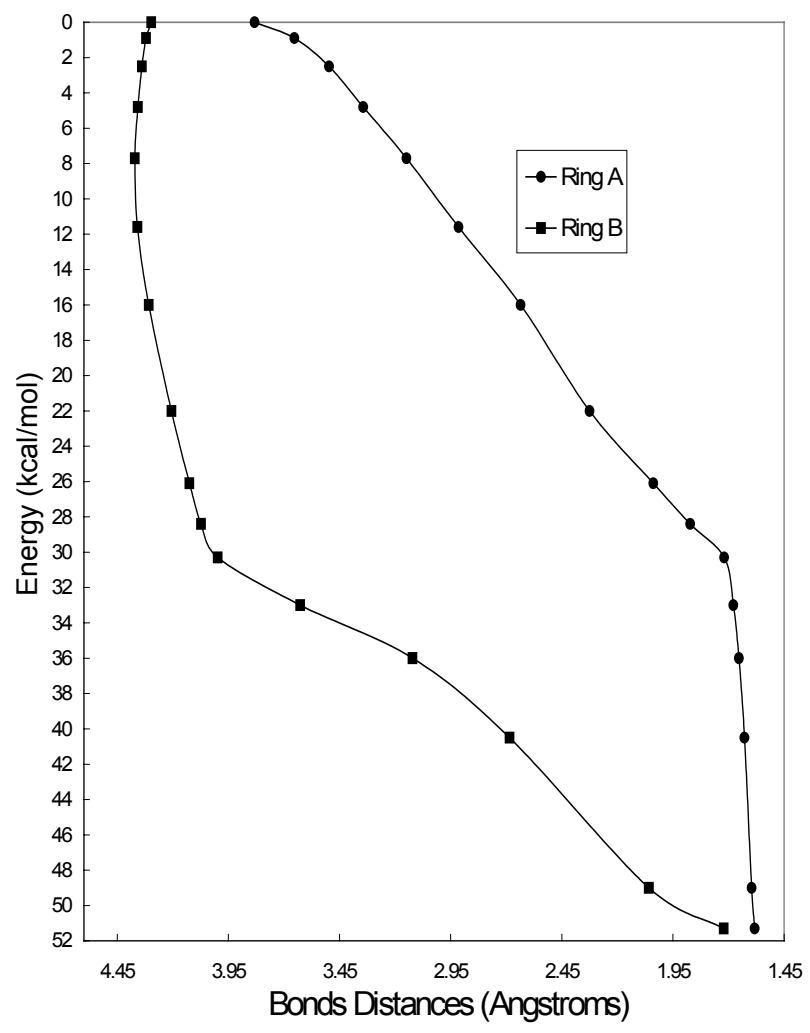

Figure S1. Plot of the MP2/6-31G* energies vs. structures of points shown in Figure 4. 